\title{
BMJ Open Cross-sectional study of the association between long working hours and pre- diabetes: 2010-2017 Korea national health and nutrition examination survey
}

Yunseng Baek, ${ }^{1}$ Minseok Kim, ${ }^{1}$ Gyu Ri Kim (D) , ${ }^{2}$ Eun-Cheol Park (D) ${ }^{2,3}$

To cite: Baek Y, Kim M, Kim GR, et al. Cross-sectional study of the association between long working hours and prediabetes: 2010-2017 Korea national health and nutrition examination survey. BMJ Open 2019;9:e033579. doi:10.1136/ bmjopen-2019-033579

- Prepublication history for this paper is available online. To view these files, please visit the journal online (http://dx.doi. org/10.1136/bmjopen-2019033579).

YB and MK contributed equally.

Received 12 August 2019 Revised 25 November 2019 Accepted 26 November 2019

Check for updates

(c) Author(s) (or their employer(s)) 2019. Re-use permitted under CC BY-NC. No commercial re-use. See rights and permissions. Published by BMJ.

${ }^{1}$ Premedical courses, Yonsei University College of Medicine, Seoul, Korea (the Republic of) ${ }^{2}$ Department of Preventive Medicine, Yonsei University College of Medicine, Seoul, Korea (the Republic of)

${ }^{3}$ Department of Preventive Medicine and Institute of Health Services Research, Yonsei University College of Medicine, Seoul, Korea (the Republic of)

Correspondence to Dr Eun-Cheol Park; ecpark@yuhs.ac

Dr Gyu Ri Kim; gyurikim@yuhs.ac

\section{ABSTRACT}

Objective Long working hours have been shown to raise the risk of various health outcomes. However, epidemiological evidence has shown inconsistent result in relation to type 2 diabetes mellitus (T2DM) and the association between long working hours and pre-diabetes among non-diabetic adults remains largely unexplored. We thus aimed to investigate whether long working hours were linked with pre-diabetes as determined by glycated haemoglobin (HbA1c) level.

Design Cross-sectional survey.

Participants This study included 6324 men and 4001 women without diabetes from the 2010 to 2017 Korean National Health and Nutrition Examination Survey.

Primary outcome measures The study outcome of interest was pre-diabetes, defined as $\mathrm{HbA} 1 \mathrm{c}$ values $5.7 \%$ to $6.4 \%$

Results Logistic regression was performed to obtain the ORs for pre-diabetes according to categories of work hour (40 hours/week, 41 to 52 hours/week, $>52$ hours/week), after adjusting for relevant covariates. Of the 10325 eligible participants, 2261 (34.4\%) men and 1317 (31.0\%) women had pre-diabetes. No statistically significant relationship was found for women. In men, extended working hours ( $>52$ hours per week) was associated with an increased likelihood of pre-diabetes, after adjustment for age, educational attainment, monthly household income, lifestyle related factors, perceived stress, family history of diabetes, hypertension, hypercholesterolaemia and other covariates (adjusted $\mathrm{OR}=1.22 ; 95 \% \mathrm{Cl} 1.03$ to 1.46). In the subgroup analysis by occupational categories, the association was only apparent among men in bluecollar worker groups.

Conclusion Extended working hours were significantly related to pre-diabetes in men, with no statistically significant association observed for women. Further subgroup analysis by occupational categories revealed that the increased odds of pre-diabetes associated with long working hours was only apparent among male workers of blue-collar occupations and shift workers.

\section{INTRODUCTION}

Pre-diabetes, defined as an intermediate state of hyperglycaemia with glycaemic parameters above normal but below the diagnostic threshold for diabetes is considered an
Strengths and limitations of this study

- As far as we are aware, this is the first report of an association between long working hours and prediabetes among individuals without diabetes using a nationally representative sample of Korean adults. We further compared associations by occupational categories.

- This study controlled for a range of factors that are known to affect glycated haemoglobin levels.

- Our analyses are based on cross-sectional data and, as such, preclude direct causal inference.

important risk factor for $\beta$-cell dysfunction ${ }^{1}$ and the development of type 2 diabetes mellitus (T2DM). ${ }^{2}$ According to the 2012 projection estimates, prevalence of prediabetes will continue to rise, and it is estimated that by 2030 over 470 million people will have pre-diabetes globally. ${ }^{3}$ Approximately $70 \%$ of individuals diagnosed with pre-diabetes are expected to progress to T2DM within 10 years. ${ }^{4}$ Given the high incidence rate of diabetes among pre-diabetic adults, identification of the modifiable risk factors of pre-diabetes in the general population is thus essential to effectively prevent or delay the onset of diabetes and its associated complications.

South Korea has one of the longest work hours among member states of the Organisation for Economic Cooperation and Development (OECD), with people spending on average 2069 hours at work annually compared with the OECD average of 1764 hours. $^{5}$

Several studies have assessed long working hours in relationship with the risk of various health outcomes, including coronary heart disease, ${ }^{67}$ cognitive function, ${ }^{8}$ as well as a high prevalence of anxiety ${ }^{9}$ and sleeping disturbances. ${ }^{10}$ However, epidemiological evidence have shown inconsistent result in 


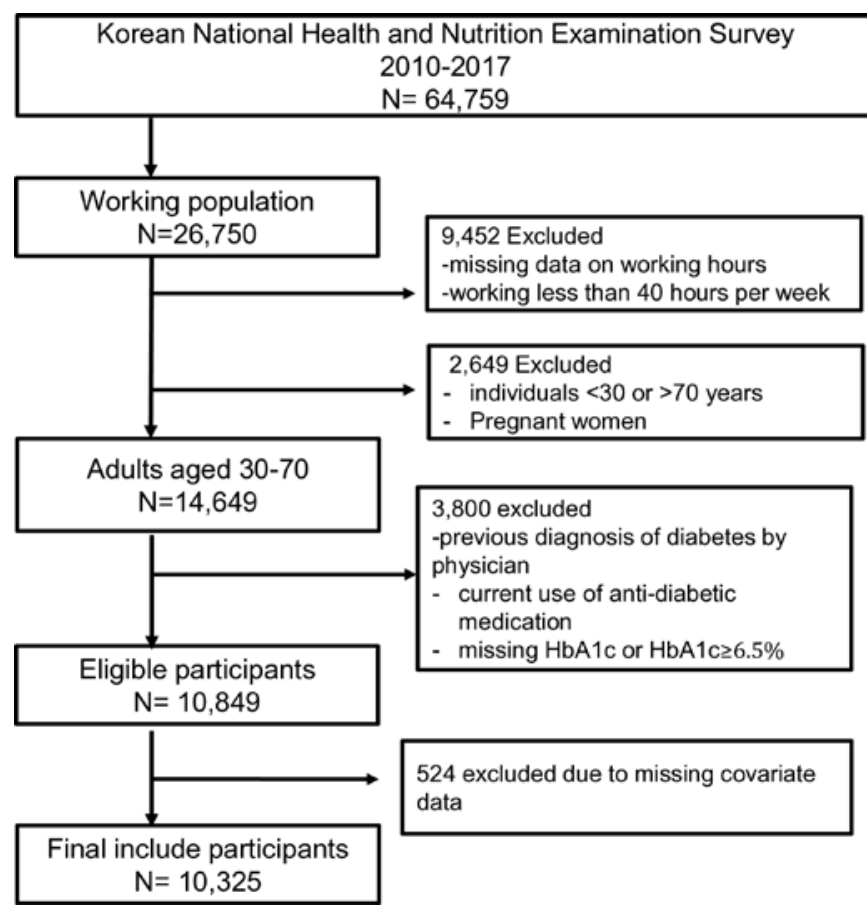

Figure 1 Flowchart of participant selection. HbA1c,glycated haemoglobin.

relation to diabetes ${ }^{11-14}$ and the association between long working hours and pre-diabetes in populations without diabetes remains largely unexplored. In a meta-analysis of epidemiological studies conducted in USA, Europe, Japan and Australia, Kivimäki et al reported a prospective association between long working hours and the incidence of diabetes, but only among employees with a low socioeconomic position. ${ }^{12}$ Similarly, one study of Chinese male workers found that the risk of developing diabetes increased with longer hours of overtime work per week. ${ }^{13}$ In contrast, in a study of Japanese male workers, the relative risk of type 2 diabetes significantly decreased among those who worked over 10 hours a day compared with those who worked 7 to 8 hours. ${ }^{14}$ To fill this evidence gap, we investigated the relationship between weekly working hours and the pre-diabetes using a cross-sectional survey of 10325 workers in South Korea.

\section{METHODS}

\section{Study population}

Data were drawn from the 2010 to 2017 Korean National Health and Nutrition Examination Survey (KNHANES). KNHANES is an ongoing population based, crosssectional study which is designed to assess the health and nutritional status of people residing in South Korea. ${ }^{15}$ The survey's sampling strategy was designed to be representative of the non-institutionalised civilian population aged 1 year or over, which was selected using a complex, multistage, stratified sampling design. Of the 64759 participants (men: 29 458, women: 35 301) who participated in the 2010 to 2017 survey, 26750 reported as being economically active and therefore were eligible to be asked job-related modules and 26696 provided valid responses concerning weekly work hours. We restricted analyses to individuals working 40 hours or more per week, as participants who worked for less than 40 hours are likely to do so due to health reasons $(\mathrm{n}=17298)$. Additionally, KNHANES participants under 30 or $>70$ years old and pregnant women were excluded from the analysis $(n=2649)$. We also excluded those who reported a previous clinical diagnosis of diabetes made by a physician or taking insulin or antidiabetic medication or missing data on glycated haemoglobin (HbA1c), or HbA1c values greater than $6.5 \%(n=3800)$. Finally, we excluded participants with missing covariate data $(n=524)$, yielding a final sample of 10325 participants (men: 6324, women: 4001) (see figure 1).

\section{Patient and public involvement}

No patients were included in the design and planning of the study. Including patientand public involvement (PPI) statements aligns closely with BMJ Open's values of transparency and inclusiveness. We hope that including PPI statements in all articles is the first step of many for BMJ Open in encouraging patient involvement.

\section{Measures}

Definition of pre-diabetes

The main study outcome was HbAlc. HbAlc is a form of haemoglobin in which glucose is attached to its $\beta$-chain after exposure to high plasma levels of glucose. As such, it is used as an integrated index of long-term serum glucose regulation. ${ }^{16}$ Fasting bloods samples were collected during a medical examination and HbA1c levels were measured via high performance liquid chromatography (HLC-723G7; Tosoh, Tokyo, Japan). Participants were identified as being normoglycaemic if they had a HbA1c level below 5.7\%; HbAlc level between 5.7 and 6.4 per cent were indicative of pre-diabetes according to the 2018 American Diabetes Association standards of care in diabetes. ${ }^{17}$ Previous research has indicated that HbA1c and fasting blood glucose are equally in the detection of type 2 diabetes. ${ }^{18}$ Also, HbAlc has several advantages to the fasting blood sugar, including the ability to use nonfasting blood samples, greater pre-analytical stability and less day-to-day perturbations during periods of stress and illness. $^{19}$

\section{Working hours}

In the KNHANES, participants were asked about their working hours using the following question: 'During the last month, how many hours on average in a week did you work, including unpaid overtime work (excluding meal time)?' In Korea, statutory weekly work hours based on the Labour Standards Act (LSA) are 40 hours per week and 8 hours per day. The working hours stipulated in LSA Article 50 may be extended up to additional 12 hours by agreement between the parties. Therefore, in the current study we defined long working hours as working beyond the legal threshold of 52 hours. Participants reported 
their working hours as a continuous variable, and this was further categorised as follows: 40 hours, 41 to 52 hours or $>52$ hours per week.

\section{Covariates}

Data on socio-demographic characteristics, lifestylerelated and health-related factors were collected using interviewer-administered standardised questionnaires. Age was categorised into 30 to 39, 40 to 49, 50 to 59 and $\geq 60$ years. Participants were categorised by educational attainment (elementary school, middle school, high school and university degree or above), monthly household income quartiles and occupational categories (white-collar (managers, professionals), pink-collar (clerks, service and sales workers), green-collar (agricultural, fishery or forestry workers) and blue-collar (craft/ trades workers, machine operators and assemblers and elementary manual workers)). ${ }^{20}{ }^{21}$ Work schedules were assessed using the following question: 'Do you work mostly during the day time, or do you work at a different time period?' Respondent who usually worked during the daytime (06:00 to $18: 00)$, evening hours (14:00 to 24:00) or night-time (21:00 to 08:00) were categorised as fixed schedule workers, while those who worked 24 hours rotating shifts, split shifts or irregular shifts were classified as shift schedule workers.

Health-related behaviours included smoking status (never smoker, former smoker and current smoker) alcohol consumption (yes or no), muscle strengthening activity at least twice a week (yes/no), participation in aerobic activity, defined as walking at least $10 \mathrm{~min}$ at a time, for $30 \mathrm{~min}$ or more per day, on five or more per days during the 7 days preceding the survey and sleep duration $(<6,6$ to $8, \geq 9$ hours). Body mass index (BMI) was used to determine obesity status and calculated based on respondent's self-reported height and weight. A BMI of $<18.5$ $\mathrm{kg} / \mathrm{m} 2$ was considered underweight, a BMI $>18.5-22.9$ $\mathrm{kg} / \mathrm{m}^{2}$ was considered normal weight, a BMI 23.0-24.9 $\mathrm{kg} / \mathrm{m}^{2}$ was considered overweight and a BMI $\geq 25.0 \mathrm{~kg} /$ $\mathrm{m}^{2}$ was considered obese. The level of perceived stress was measured using the following question: "How stressed are you on a daily basis?' with possible answers ranging from 'None' coded 0 to 'High' coded 4. Respondents were reclassified into low (none/low) and high perceived stress (moderate/high). Hypercholesterolaemia (yes/no) was defined as a serum total cholesterol level $\geq 240 \mathrm{mg} / \mathrm{dL}$ or the use of lipid-lowering medications. Hypertension (yes/ no) was defined as a systolic blood pressure of $140 \mathrm{~mm}$ $\mathrm{Hg}$ or higher, diastolic blood pressure of $90 \mathrm{~mm} \mathrm{Hg}$ or higher or on antihypertensive treatment. A family history of diabetes was ascertained by asking participants whether their first-degree relatives (parents or siblings) had ever been told they have diabetes (yes/no).

\section{Statististical analyses}

Statistical analyses were conducted using SAS V.9.4 (SAS Institute Inc, Cary, North Carolina, USA). The SAS survey procedure was applied to reflect the stratification and clustering of the complex sampling design and sampling weights of the KNHANES and to ensure nationally representative prevalence estimates. General characteristics of the study sample were described using frequency and weighted percentages. $\mathrm{X}^{2}$ test was used to compare participant characteristics across working hours and between normoglycaemic and pre-diabetic subjects. Multivariable logistic regression analysis was used to evaluate the association between working hours and pre-diabetes status, and ORs and $95 \%$ CI were calculated after adjusting for socio-demographic and health-related behavioural variables that showed significant association in univariate analysis and based on clinical relevance. Additionally, we evaluated whether the association between long working hours and pre-diabetes was dependent on age or workrelated characteristics by testing interaction effects and conducting subgroup analyses. Interaction was assessed by including a cross-product interaction term (working hour $\times$ effect modifier variable) in the logistic regression model along with the main effect. All analyses were performed separately for men and women. All reported $p$ values were based on two-sided tests; statistical significance was set at $\mathrm{p}<0.05$.

\section{RESULTS}

\section{General characteristics of the study population}

Table 1 presents participants' general characteristics by HbA1c status in men and women. A total of 2261 $(34.43 \%)$ men and $1317(31.04 \%)$ women had prediabetes. Men who worked 40 hours per week had the lowest pre-diabetes prevalence $(30.92 \%)$, followed by those working 41 to 52 hours $(32.88 \%)$ and $>52$ hours $(38.00 \%)$. Male workers with pre-diabetes were also more likely to be older, have lower levels of household income and education, to be working in a manual occupations, obese, current smokers, sleep less than 6 hours and to have a diagnosis of hypertension, hypercholesterolaemia and a family history of diabetes compared with normoglycaemic subjects. For women, we observed statistically significant differences in prevalence of pre-diabetes for most characteristics, except for participation in aerobic activity, muscle strengthening activity, family history of diabetes and work schedule.

Table 2 shows characteristics of study participants according to categories of working hours. A total of 1399 (22.08\%) male participants reported 40 hours of work per week, $2483(39.03 \%)$ reported 41 to 52 hours and 2442 $(38.89 \%)$ reported more than 52 hours of work per week; the corresponding values for women were 1086 (27.49\%), $1574(39.19 \%)$ and $1341(33.32 \%)$, respectively. Participants who worked more than 52 hours were more likely to be older, have lower education, lower household income, higher self-perceived stress, in blue-collar occupation and have shift work schedule compared with men who work 40 hours per week. As regard health-related variables, subjects who worked more than 52 hours tended to be current smoker, non-drinker, have shorter sleep duration 
Table 1 General characteristics of the study population by HbA1c status, KNHANES 2010-2017

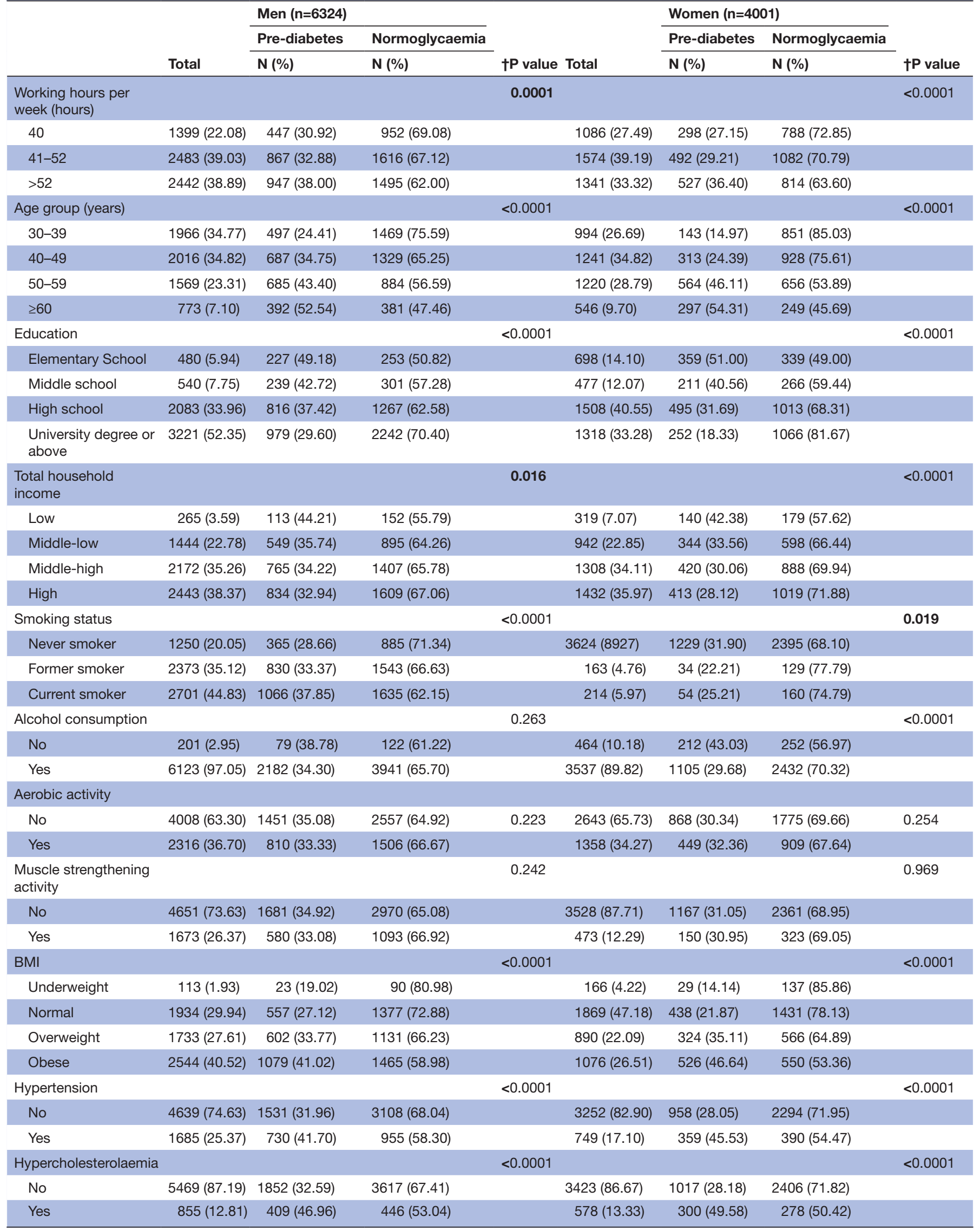

Continued 


\begin{tabular}{|c|c|c|c|c|c|c|c|c|}
\hline & & Men $(n=6324)$ & & & & Women $(n=40 c$ & & \\
\hline & & Pre-diabetes & Normoglycaemia & & & Pre-diabetes & Normoglycaemia & \\
\hline & Total & N (\%) & N (\%) & †P value & Total & N (\%) & N (\%) & †P value \\
\hline No & 5045 (79.35) & 1739 (32.70) & 3306 (67.30) & & 3086 (76.91) & $1003(30.79)$ & $2083(69.21)$ & \\
\hline Yes & 1279 (20.65) & $522(41.09)$ & 757 (58.91) & & 915 (23.09) & $314(31.87)$ & $601(68.13)$ & \\
\hline$<6$ & $738(11.62)$ & $282(36.32)$ & $456(63.68)$ & & $562(14.49)$ & $223(39.68)$ & $339(60.32)$ & \\
\hline $6-8$ & $5167(82.16)$ & 1850 (34.59) & $3317(65.41)$ & & $3083(76.56)$ & 996 (29.91) & 2087 (70.09) & \\
\hline$\geq 9$ & $419(6.22)$ & $129(28.90)$ & $290(71.10)$ & & $356(8.95)$ & 98 (26.69) & $258(73.31)$ & \\
\hline Perceived stress & & & & 0.553 & & & & 0.008 \\
\hline None/low & $4513(70.82)$ & 1633 (34.68) & $2880(65.32)$ & & 2743 (67.68) & 945 (32.51) & $1798(67.49)$ & \\
\hline Pink-collar & 859 (14.05) & $317(36.50)$ & $542(63.50)$ & & 1263 (32.68) & $493(36.87)$ & $770(63.13)$ & \\
\hline Green-collar & $356(4.20)$ & $163(44.57)$ & $193(55.43)$ & & $309(5.45)$ & 169 (52.94) & $140(47.06)$ & \\
\hline Blue-collar & $2335(37.27)$ & $936(38.40)$ & $1399(61.60)$ & & $902(23.61)$ & $344(37.15)$ & $558(62.85)$ & \\
\hline Work schedule & & & & 0.998 & & & & 0.290 \\
\hline Fixed & $5801(92.25)$ & $2060(34.43)$ & $3741(65.57)$ & & $3826(32.11)$ & $1255(30.83)$ & $2571(69.17)$ & \\
\hline Shift & $523(7,75)$ & $201(34.44)$ & $322(65.56)$ & & 175 (22.05) & $62(35.09)$ & $113(64.91)$ & \\
\hline Participants & & 2261 (34.43) & $4063(65.57)$ & & & 1317 (31.04) & 2684 (68.96) & \\
\hline
\end{tabular}

BMI, body mass index; HbA1c, glycated haemoglobin; KNHANES, Korean National Health and Nutrition Examination Survey.

and less likely to engage in muscle strengthening activity. Among women, no appreciable differences in smoking status, muscle strengthening activity and work schedule were apparent across working hours per week.

\section{Association between long working hours and pre-diabetes}

Results from the logistic regression analysis are shown in table 3. In univariate logistic regression analyses, long working hours was significantly associated with increased odds of having pre-diabetes in both men and women. Compared with the individuals who worked 40 hours, the ORs of pre-diabetes for the those who belong to the $>52$ hours category were 1.37 (95\% CI 1.17 to 1.61 ; $p$ for trend <0.0001) and 1.54 (95\% CI 1.25 to 1.88; p for trend $<0.0001)$ for men and women, respectively. For women, the positive association between the working hours and pre-diabetes was no longer significant after controlling for age, with OR of 1.06 (95\% CI 0.84 to 1.32). In the case of men, those who worked $>52$ hours were 1.22 times more likely to have pre-diabetes after adjusting for covariates (multivariable-adjusted OR: 1.22; 95\% CI: 1.03 to 1.46; p for trend 0.017). Age, smoking status, hypercholesterolaemia, family history of diabetes and sleep duration were also found to be associated with increased odds of prediabetes in men, but there were no statistically significant differences based on educational level, monthly household income, alcohol consumption, muscle strengthening activity, hypertension, perceived stress, occupation and work schedule.

Table 4 presents the ORs for subgroup analyses by age and work-related characteristics. We did not observe a significant interaction between the number of hours worked per week and age (men: $\mathrm{P}$ for interaction=0.309) nor between work schedule and working hours (men: $\mathrm{P}$ for interaction $=0.864$ ). The relationship between long working hours and pre-diabetes was more pronounced among male shift workers, although not statistically significantly, (41 to 52 hours: adjusted OR $(\mathrm{aOR})=1.64$, $95 \%$ CI 0.77 to $3.47 ;>52$ hours: aOR $=1.64,95 \%$ CI 0.78 to 3.44 ; $\mathrm{p}$ for interaction $=0.864$ ). In the subgroup analysis by occupational categories, male workers who worked in blue-collar occupation were likely to have pre-diabetes as their average weekly working hours increased, after adjustment for all covariates. The adjusted ORs were 1.13 (95\% CI 0.84 to 1.53 ) and 1.54 (95\% CI 1.15 to 2.06) for the 41 to 52 hours and $>52$ hours categories, respectively ( $p$ for trend=0.041). However, the interaction effect by occupational categories was not statistically significant ( $p$ for interaction=0.146). 
Table 2 General characteristics of the study population according to working hours per week, KNHANES 2010-2017

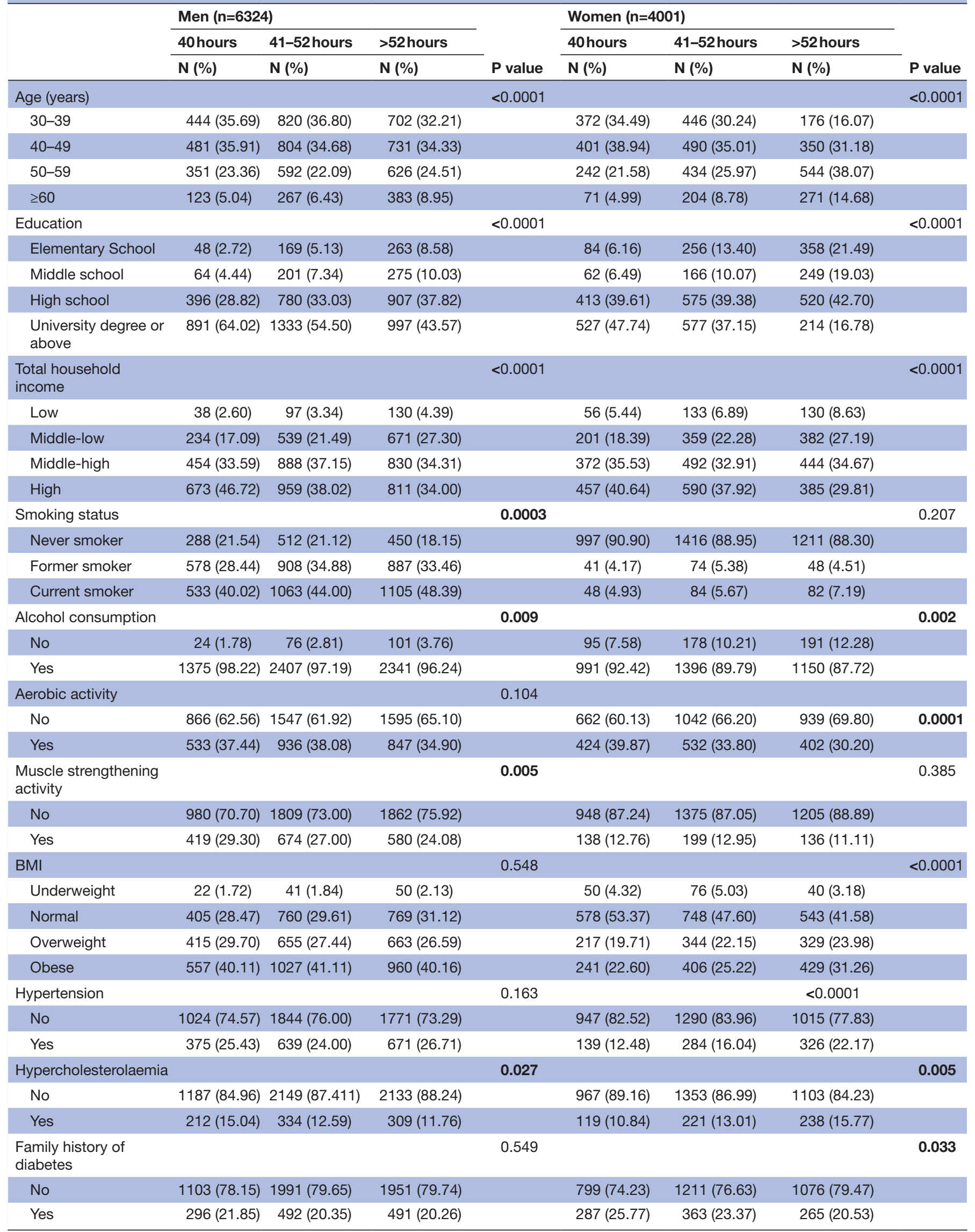


Table 2 Continued

\begin{tabular}{|c|c|c|c|c|c|c|c|c|}
\hline & \multicolumn{3}{|c|}{ Men $(n=6324)$} & \multirow[b]{3}{*}{$P$ value } & \multicolumn{3}{|c|}{ Women $(n=4001)$} & \multirow[b]{3}{*}{$P$ value } \\
\hline & 40 hours & 41-52 hours & $>52$ hours & & 40 hours & 41-52 hours & $>52$ hours & \\
\hline & N (\%) & N (\%) & N (\%) & & N (\%) & N (\%) & N (\%) & \\
\hline$<6$ & $120(8.63)$ & $256(10.72)$ & $362(14.22)$ & & $128(12.06)$ & $209(14.35)$ & $225(16.65)$ & \\
\hline $6-8$ & $1182(84.61)$ & $2070(83.19)$ & $1915(79.74)$ & & 836 (76.99) & $1223(76.30)$ & $1024(76.50)$ & \\
\hline None/low & $1083(76.16)$ & $1785(71.21)$ & $1645(67.39)$ & & $788(71.80)$ & $1076(67.40)$ & $879(64.41)$ & \\
\hline Moderate/high & $316(23.84)$ & 698 (28.79) & $797(32.61)$ & & $298(28.20)$ & $498(32.60)$ & $462(35.39)$ & \\
\hline Occupation & & & & $<0.0001$ & & & & $<0.0001$ \\
\hline White-collar & $873(61.51)$ & $1200(49.05)$ & $701(30.23)$ & & $665(60.23)$ & $672(42.70)$ & $190(14.90)$ & \\
\hline Work schedule & & & & $<0.0001$ & & & & 0.283 \\
\hline Fixed & $1334(95.41)$ & 2297 (92.38) & $2170(90.33)$ & & $1034(94.20)$ & 1507 (95.77) & $1285(95.41)$ & \\
\hline Shift & $65(4.59)$ & $186(7.62)$ & $272(9.67)$ & & $52(5.80)$ & $67(4.23)$ & $56(4.59)$ & \\
\hline Participants & $1399(22.08)$ & 2483 (39.03) & $2442(38.89)$ & & $1086(27.49)$ & 1574 (39.19) & 1341 (33.32) & \\
\hline $\begin{array}{l}\text { *Unless otherwise state } \\
\text { (weighted \%) are show }\end{array}$ & $\begin{array}{l}\text { d, unweighted } \\
\text { n. }\end{array}$ & frequency & & & & & & \\
\hline Row percentages are & hown. & & & & & & & \\
\hline
\end{tabular}

BMI, body mass index; KNHANES, Korean National Health and Nutrition Examination Survey.

Model 2 adjusted for age, educational attainment, total household income, obesity, smoking status, alcohol consumption, participation in aerobic activity, muscle strengthening activity, hypertension, hypercholesterolaemia, family history of diabetes, sleep duration, perceived stress, occupation, work schedule.

\section{DISCUSSION}

In this population-based study of Korean working adults without diabetes, we found that men who worked over 52 hours per week exhibited $22 \%$ increased odds for pre-diabetes than did those who worked 40 hours per week. This association was robust to adjustments for socio-demographic variables and lifestyle factors, such as obesity, participation in aerobic and muscle strengthening activity, smoking and alcohol consumption and other covariates. Importantly, we found that the increased odds of pre-diabetes associated with long working hours was - although not statistically significant - more pronounced among workers of blue-collar occupations and shift workers. These findings are in line with the evidence from a prospective study conducted in Japan which found that long working hours are related to the risk of incident diabetes among shift workers. ${ }^{22}$ Further studies with larger sample sizes are warranted to explore whether the lack of statistical significance observed is a result of sample size, or reflects a true lack of association.
Additionally, assessment of additive interaction between long working hours and lifestyle factors would be a fruitful venue for further research for more in depth understanding of the impacts of such interaction.

In the present study, the prevalence of pre-diabetes in the Korean working population was $34.4 \%$ and $31.0 \%$ for men and women, respectively. These prevalence estimates are comparable to general population estimates reported in the USA, ${ }^{23} \mathrm{UK}^{24}$ and those of other Asian countries. ${ }^{25}$ Several previous studies have yielded prevalence estimates for pre-diabetes in Korea. Using the HbA1c cut-off, pre-diabetes prevalence in 2011 was reported to be $38.3 \%$ (men: $41 \%$; women: $35.7 \%$ ) in a community-based crosssectional study of Korean adults aged 30 years or over. ${ }^{26}$ Another Korean study reported a pre-diabetes prevalence of $26.1 \%$ in men and $20.5 \%$ according to American Diabetes Association criteria. ${ }^{27}$ However, this study was based on a sample from rural areas. Pre-diabetes is a wellrecognised risk factor for future diabetes, that gives rise to microvascular and macrovascular complications and have enormous social and economic burden ${ }^{28} 29$; increased attention needs to be paid to the high prevalence of prediabetes in Korea.

We are not aware of other studies that has reported a relationship between long working hours and prediabetes, although our findings are comparable with a meta-analysis showing that long working hours is 
Table 3 Results of the logistic regression analysis for the association between long working hours and pre-diabetes (HbA1c $5.7 \%$ to $6.4 \%)$

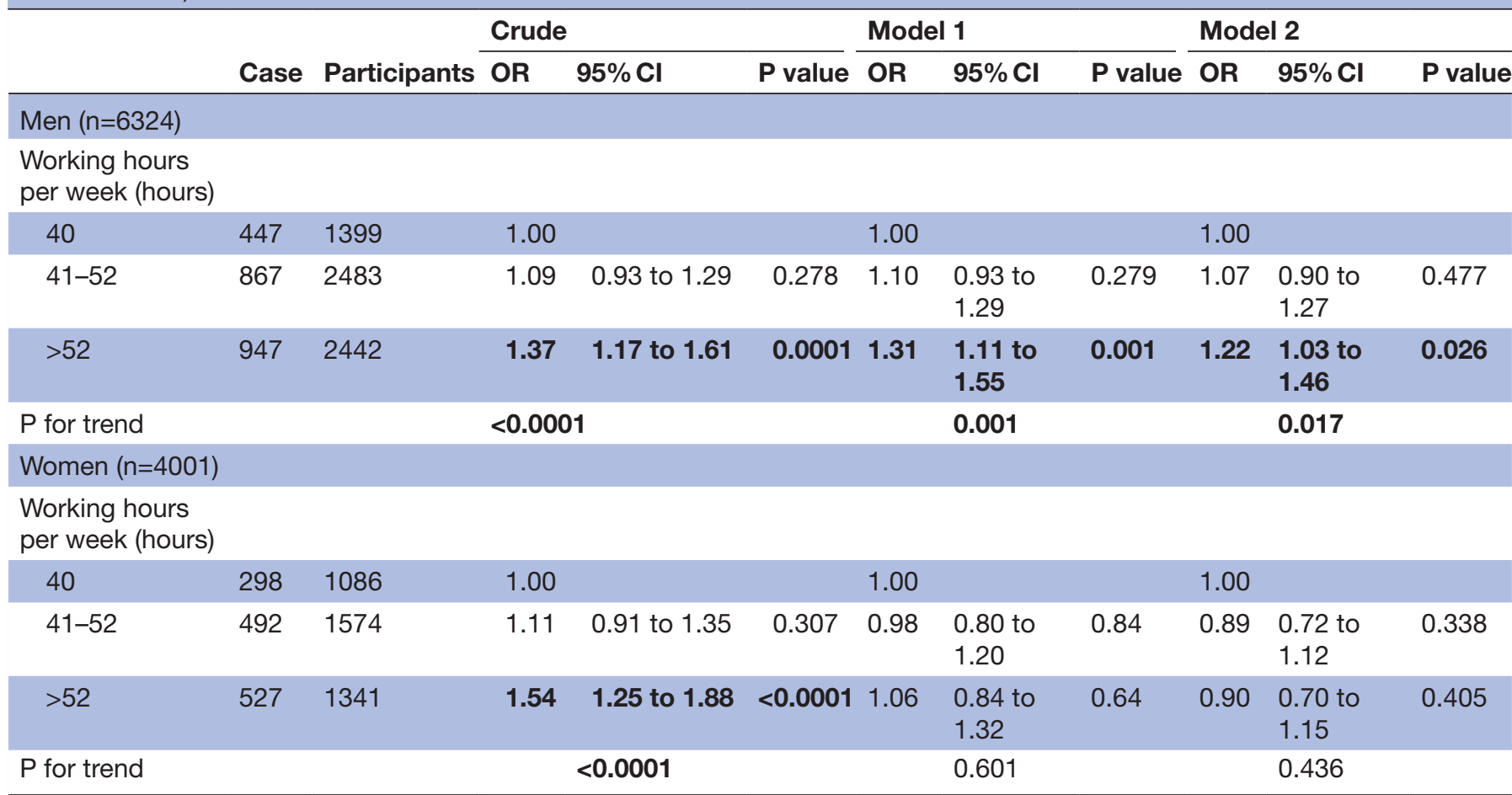

Model one adjusted for age.

HbA1c, glycated haemoglobin.

associated with the incidence of type 2 diabetes among individuals from low socioeconomic status groups. ${ }^{12}$ Another study have also reported a similar finding, indicating that extended working hours is positively correlated with non-insulin dependent diabetes mellitus in men. ${ }^{30}$ However, our results conflict with a previous study that found relative risks of T2DM significantly decreased with an increase in hours of work per day. ${ }^{14}$

The mechanisms underlying the association between long working hours and pre-diabetes are yet unknown. It is likely that a similar mechanism to that of diabetes could be responsible for the observed findings. Plausible explanations are that longer working hours impacts prediabetes risk via their association with behavioural risk factors. As shown in this study, prior research has indicated that working longer than recommended hours is linked to many behavioural risk factors, such as binge drinking $^{31}{ }^{32}$ and low physical activity, ${ }^{33}$ possibly because individuals feel that they lack the time to engage in leisure-time physical activity due to demands and responsibilities at work. In the present study, working hour prediabetes association attenuated but remained statistically significant in men after adjustment for behavioural risk factors. As such, conventional risk factors for pre-diabetes are likely to explain only part of the association between long working hours and pre-diabetes.

Meanwhile, there has been a proposition that extended working hours are related to cortisol secretion, ${ }^{34}$ a known risk factor for impaired glucose metabolism. ${ }^{35}$ Cortisol induces the formation of glucose in the liver and have insulin-antagonistic effects in the peripheral tissues; both processes have the potential to contribute to risk of hyperglycaemia. Furthermore, individuals working longer hours are more often exposed to harmful psychological factors in the work environment, such as job strain ${ }^{36} 37$ and effort-reward imbalance, ${ }^{38}$ which are known to be associated with subsequent elevation of HbA1c. ${ }^{39}$ As such, stress-related mechanisms that trigger dysregulation of neuroendocrine pathways, might be a potentially promising areas for future research studying the differences in risk of pre-diabetes according to work hours.

The present study has several strengths. First, this study is based on a nationally representative survey, and to the best of our knowledge, this is the first report of an association between long working hours and pre-diabetes among individuals without diabetes. Second, blood samples were collected using standardised laboratory procedures, ensuring an accurate estimate of HbAlc. Finally, we were able to control for several important confounding variables, such as sleep duration and perceived control. However, this study is not without limitations. Our analyses are based on data from observational studies and, as such, preclude direct causal inference. Information on working hours and other covariates were self-reported and thus subject to recall bias. Moreover, we cannot exclude the possibility that the results were affected by residual confounding caused by imprecisely measured covariates or some other unmeasured occupational 
Table 4 Results of subgroup analysis of association between pre-diabetes and working hours by age and work characteristics

\begin{tabular}{|c|c|c|c|c|c|c|c|}
\hline \multirow[b]{2}{*}{ Characteristics } & \multirow[b]{2}{*}{ Case } & \multirow[b]{2}{*}{ Participants } & \multicolumn{3}{|c|}{ OR $(95 \% \mathrm{Cl})$} & \multirow{2}{*}{$\begin{array}{l}\mathrm{P} \text { for } \\
\text { trend }\end{array}$} & \multirow{2}{*}{$\begin{array}{l}\text { P for } \\
\text { interaction }\end{array}$} \\
\hline & & & 40 hours & 41-52hours & $>52$ hours & & \\
\hline \multicolumn{8}{|l|}{ Men $(n=6324)$} \\
\hline $\begin{array}{l}\text { Occupational } \\
\text { categories }\end{array}$ & & & & & & & 0.146 \\
\hline White-collar & 845 & 2774 & 1.00 & 1.04 (0.83 to 1.30$)$ & 1.06 (0.82 to 1.38$)$ & 0.664 & \\
\hline Pink-collar & 317 & 859 & 1.00 & $1.22(0.72$ to 2.06$)$ & 0.99 (0.60 to 1.65$)$ & 0.714 & \\
\hline Green-collar & 163 & 356 & 1.00 & $0.52(0.16$ to 1.65$)$ & 0.90 (0.32 to 2.55$)$ & 0.247 & \\
\hline Blue-collar & 936 & 2335 & 1.00 & 1.13 (0.84 to 1.53$)$ & 1.54 (1.15 to 2.06$)$ & 0.001 & \\
\hline Work schedule & & & & & & & 0.864 \\
\hline Fixed & 2060 & 5801 & 1.00 & 1.04 (0.87 to 1.25$)$ & 1.21 (1.01 to 1.45$)$ & 0.031 & \\
\hline Shift & 201 & 523 & 1.00 & 1.64 (0.77 to 3.47$)$ & 1.64 (0.78 to 3.44$)$ & 0.317 & \\
\hline Age (years) & & & & & & & 0.309 \\
\hline 30-39 & 497 & 1966 & 1.00 & 1.31 (0.94 to 1.83$)$ & 1.44 (1.01 to 2.06 ) & 0.047 & \\
\hline $40-49$ & 687 & 2016 & 1.00 & 0.89 (0.67 to 1.19$)$ & 1.20 (0.89 to 1.61$)$ & 0.124 & \\
\hline $50-59$ & 685 & 1569 & 1.00 & 1.05 (0.76 to 1.47$)$ & 1.11 (0.80 to 1.55$)$ & 0.529 & \\
\hline$\geq 60$ & 392 & 773 & 1.00 & 1.29 (0.77 to 2.17$)$ & 1.12 (0.68 to 1.87$)$ & 0.079 & \\
\hline \multicolumn{8}{|l|}{ Women $(n=4001)$} \\
\hline $\begin{array}{l}\text { Occupational } \\
\text { categories }\end{array}$ & & & & & & & 0.442 \\
\hline White-collar & 311 & 1527 & 1.00 & 1.14 (0.82 to 1.60$)$ & 0.78 (0.48 to 1.27$)$ & 0.619 & \\
\hline Pink-collar & 493 & 1263 & 1.00 & 0.62 (0.39 to 0.98$)$ & 0.77 (0.50 to 1.19$)$ & 0.706 & \\
\hline Green-collar & 169 & 309 & 1.00 & 1.42 (0.45 to 4.45$)$ & 0.94 (0.30 to 2.93 ) & 0.309 & \\
\hline Blue-collar & 344 & 902 & 1.00 & 0.89 (0.58 to 1.35$)$ & 0.93 (0.59 to 1.45$)$ & 0.769 & \\
\hline Work schedule & & & & & & & 0.202 \\
\hline Fixed & 1255 & 3826 & 1.00 & 0.85 (0.68 to 1.06$)$ & 0.87 (0.68 to 1.11$)$ & 0.302 & \\
\hline Shift & 62 & 175 & 1.00 & 2.71 (0.88 to 8.30$)$ & 2.57 (0.80 to 8.25$)$ & 0.121 & \\
\hline Age (years) & & & & & & & 0.978 \\
\hline $30-39$ & 143 & 994 & 1.00 & 0.79 (0.48 to 1.29$)$ & 0.79 (0.39 to 1.58$)$ & 0.451 & \\
\hline $40-49$ & 313 & 1241 & 1.00 & 0.89 (0.62 to 1.31$)$ & 0.81 (0.54 to 1.23 ) & 0.327 & \\
\hline $50-59$ & 564 & 1220 & 1.00 & 0.95 (0.64 to 1.39$)$ & 1.02 (0.69 to 1.52$)$ & 0.828 & \\
\hline$\geq 60$ & 297 & 546 & 1.00 & 0.94 (0.46 to 1.92$)$ & 0.82 (0.42 to 1.62$)$ & 0.485 & \\
\hline
\end{tabular}

factors, such as job strain and job satisfaction. Working hours was measured at a single point in time that might not represent long-term exposure. In future studies, use of repeated measurements is needed to characterise longitudinal relation between long working hours and pre-diabetes.

\section{CONCLUSIONS}

In conclusion, extended working hours in men was significantly correlated with the odds of pre-diabetes, independent of conventional risk factors. No statistically significant relationship was found for women. In the subgroup analysis, the association between long working hours and pre-diabetes was apparent only in male workers of blue-collar occupations and shift workers. Additional large-scale longitudinal studies are needed to verify these findings.

Contributors BYS, MK, GRK contributed to the conception and design of the study. BYS, MK, GRK, ECP contributed to analyses and interpretation of the data. BYS, MK, GRK drafted the manuscript. All authors read and approved the final manuscript.

Funding The authors have not declared a specific grant for this research from any funding agency in the public, commercial or not-for-profit sectors.

Competing interests None declared.

Patient consent for publication Not required.

Ethics approval The survey protocols for the KNHANES were approved by the Institutional Review Board of the Korea Centers for Disease Control and Prevention (IRB No. 2010-02CON-21-C, 2011-02C0N-06-C, 2012-01EXP-01-2C, 2013-07CON-03-4C, 2013-12EXP-03-5C, and 2015-01-02-6C), and informed consent was obtained from all participants.

Provenance and peer review Not commissioned; externally peer reviewed. 
Data availability statement Data used in this study are available from the KNHANES official website (http://knhanes.cdc.go.kr/).

Open access This is an open access article distributed in accordance with the Creative Commons Attribution Non Commercial (CC BY-NC 4.0) license, which permits others to distribute, remix, adapt, build upon this work non-commercially, and license their derivative works on different terms, provided the original work is properly cited, appropriate credit is given, any changes made indicated, and the use is non-commercial. See: http://creativecommons.org/licenses/by-nc/4.0/.

ORCID iDs

Gyu Ri Kim http://orcid.org/0000-0003-3624-3971

Eun-Cheol Park http://orcid.org/0000-0002-2306-5398

\section{REFERENCES}

1 Kanat M, Winnier D, Norton L, et al. The relationship between \{beta\}-cell function and glycated hemoglobin: results from the veterans administration genetic epidemiology study. Diabetes Care 2011;34:1006-10.

2 Zhang X, Gregg EW, Williamson DF, et al. A1C level and future risk of diabetes: a systematic review. Diabetes Care 2010;33:1665-73.

3 Tabák AG, Herder C, Rathmann W, et al. Prediabetes: a high-risk state for diabetes development. The Lancet 2012;379:2279-90.

4 Nathan DM, Davidson MB, DeFronzo RA, et al. Impaired fasting glucose and impaired glucose tolerance: implications for care. Diabetes Care 2007;30:753-9.

5 OECD. OECD employment outlook, 2017.

6 Virtanen M, Heikkilä K, Jokela M, et al. Long working hours and coronary heart disease: a systematic review and meta-analysis. Am J Epidemiol 2012;176:586-96.

7 Kivimäki M, Jokela M, Nyberg ST, et al. Long working hours and risk of coronary heart disease and stroke: a systematic review and metaanalysis of published and unpublished data for 603838 individuals. The Lancet 2015;386:1739-46.

8 Virtanen M, Singh-Manoux A, Ferrie JE, et al. Long working hours and cognitive function: the Whitehall II study. Am J Epidemiol 2009;169:596-605.

9 Virtanen M, Ferrie JE, Singh-Manoux A, et al. Long working hours and symptoms of anxiety and depression: a 5-year follow-up of the Whitehall II study. Psychol Med 2011;41:2485-94.

10 Bannai A, Tamakoshi A. The association between long working hours and health: a systematic review of epidemiological evidence. Scand $J$ Work Environ Health 2014;40:5-18.

11 Gilbert-Ouimet M, Ma H, Glazier R, et al. Adverse effect of long work hours on incident diabetes in 7065 Ontario workers followed for 12 years. BMJ Open Diab Res Care 2018;6:e000496.

12 Kivimäki M, Virtanen M, Kawachi I, et al. Long working hours, socioeconomic status, and the risk of incident type 2 diabetes: a meta-analysis of published and unpublished data from 222120 individuals. Lancet Diabetes Endocrinol 2015;3:27-34.

13 Tayama J, Li J, Munakata M. Working long hours is associated with higher prevalence of diabetes in urban male Chinese workers: the rosai karoshi study. Stress and Health 2016;32:84-7.

14 Nakanishi N, Nishina K, Yoshida H, et al. Hours of work and the risk of developing impaired fasting glucose or type 2 diabetes mellitus in Japanese male office workers. Occup Environ Med 2001:58:569-74.

15 Kweon S, Kim Y, Jang M-j, M-j J, et al. Data resource profile: the Korea National health and nutrition examination survey (KNHANES). Int J Epidemiol 2014;43:69-77.

16 Goldstein DE, Parker KM, England JD, et al. Clinical application of glycosylated hemoglobin measurements. Diabetes 1982;31:70-8.

17 American Diabetes Association. Standards of medical care in diabetes--2013. Diabetes Care 2013;36:S11-66.
18 Bennett CM, Guo M, Dharmage SC. $\mathrm{HbA}(1 \mathrm{c})$ as a screening tool for detection of Type 2 diabetes: a systematic review. Diabet Med 2007;24:333-43.

19 Lim W-Y, Ma S, Heng D, et al. Screening for diabetes with HbA1c: test performance of HbA1c compared to fasting plasma glucose among Chinese, Malay and Indian community residents in Singapore. Sci Rep 2018;8:12419.

20 Lee W, Yeom H, Yoon J-H, et al. Metabolic outcomes of workers according to the International standard classification of occupations in Korea. Am J Ind Med 2016;59:685-94.

21 Seok H, Choi SJ, Yoon J-H, et al. The association between osteoarthritis and occupational clusters in the Korean population: a nationwide study. PLoS One 2017;12:e0170229.

22 Bannai A, Yoshioka E, Saijo Y, et al. The risk of developing diabetes in association with long working hours differs by shift work schedules. J Epidemiol 2016;26:481-7.

23 Centers for Disease Control and Prevention, Prevention. National diabetes statistics report: estimates of diabetes and its burden in the United States, 2014. Atlanta, GA: US Department of Health and Human Services, 2014.

24 Mainous AG, Tanner RJ, Baker R, et al. Prevalence of prediabetes in England from 2003 to 2011: population-based, cross-sectional study. BMJ Open 2014;4:e005002.

25 Wang L, Gao P, Zhang M, et al. Prevalence and ethnic pattern of diabetes and prediabetes in China in 2013. JAMA 2017;317:2515-23.

26 Jeon JY, Ko S-H, Kwon H-S, et al. Prevalence of diabetes and prediabetes according to fasting plasma glucose and $\mathrm{HbA1c}$. Diabetes Metab J 2013;37:349-57.

27 Lee J-E, Jung S-C, Jung G-H, et al. Prevalence of diabetes mellitus and prediabetes in Dalseong-gun, Daegu City, Korea. Diabetes Metab J 2011;35:255-63.

28 Lee KW. Costs of diabetes mellitus in Korea. Diabetes Metab J 2011;35:567-70.

29 Susan van D, Beulens JW, van der Schouw YT, et al. The global burden of diabetes and its complications: an emerging pandemic. Eur J Cardiovasc Prev Rehabil 2001;1.

30 Kawakami N, Araki S, Takatsuka N, et al. Overtime, psychosocial working conditions, and occurrence of non-insulin dependent diabetes mellitus in Japanese men. J Epidemiol Community Health 1999:53:359-63.

31 Virtanen M, Jokela M, Nyberg ST, et al. Long working hours and alcohol use: systematic review and meta-analysis of published studies and unpublished individual participant data. BMJ 2015;350:g7772.

32 Okechukwu CA. Long working hours are linked to risky alcohol consumption. BMJ 2015;350

33 Artazcoz L, Cortès I, Escribà-Agüir V, et al. Understanding the relationship of long working hours with health status and healthrelated behaviours. J Epidemiol Community Health 2009;63:521-7.

34 Marchand A, Durand P, Lupien S. Work hours and cortisol variation from non-working to working days. Int Arch Occup Environ Health 2013;86:553-9.

35 Hackett RA, Kivimäki M, Kumari M, et al. Diurnal cortisol patterns, future diabetes, and impaired glucose metabolism in the Whitehall II cohort study. J Clin Endocrinol Metab 2016;101:619-25.

36 Kawakami N, Akachi K, Shimizu H, et al. Job strain, social support in the workplace, and haemoglobin A1c in Japanese men. Occup Environ Med 2000;57:805-9.

37 Hansen AM, Larsen AD, Rugulies $R$, et al. A review of the effect of the psychosocial working environment on physiological changes in blood and urine. Basic Clin Pharmacol Toxicol 2009;105:73-83.

38 Xu W, Hang J, Gao W, et al. Association between effort-reward imbalance and glycosylated hemoglobin ( $\mathrm{HbA} 1 \mathrm{c})$ among Chinese workers: results from SHISO study. Int Arch Occup Environ Health 2012;85:215-20.

39 Siegrist J, Li J. Work stress and altered biomarkers: a synthesis of findings based on the effort-reward imbalance model. Int J Environ Res Public Health 2017;14:1373. 